\title{
Transcutaneous penetration of a single-chain variable fragment (scFv) compared to a full-size antibody: potential tool for atopic dermatitis (AD) treatment
}

\author{
Audrey Baylet ${ }^{1,2}$, Raoul Vyumvuhore², Marine Laclaverie², Laëtitia Marchand², Carine Mainzer², Sylvie Bordes²,
} Brigitte Closs-Gonthier ${ }^{2+}$ and Laurent Delpy ${ }^{1 *+}$ (C)

\begin{abstract}
Currently, several biologics are used for the treatment of cutaneous pathologies such as atopic dermatitis (AD), psoriasis or skin cancers. The main administration routes are subcutaneous and intravenous injections. However, little is known about antibody penetration through the skin. The aim was to study the transcutaneous penetration of a reduced-size antibody as a single-chain variable fragment (scFv) compared to a whole antibody (Ab) and to determine its capacity to neutralize an inflammatory cytokine involved in AD such as human interleukin-4 (hIL-4). Transcutaneous penetration was evaluated by ex vivo studies on tape-stripped pig ear skin. ScFv and Ab visualization through the skin was measured by Raman microspectroscopy. In addition, hlL-4 neutralization was studied in vitro using HEK-Blue ${ }^{\mathrm{TM}} \mathrm{IL}-4 / \mathrm{LL}-13$ cells and normal human keratinocytes (NHKs). After $24 \mathrm{~h}$ of application, analysis by Raman microspectroscopy showed that scFv penetrated into the upper dermis while Ab remained on the stratum corneum. In addition, the anti-hIL4 scFv showed very efficient and dose-dependent hIL-4 neutralization. Thus, scFv penetrates through to the upper papillary dermis while Ab mostly remains on the surface, the anti-hIL4 scFv also neutralizes its target effectively suggesting its potential use as topical therapy for AD.
\end{abstract}

Keywords: Transcutaneous penetration, Single-chain variable fragment, Antibody, Atopic dermatitis

\section{Introduction}

Currently, immunotherapy is used for the treatment of several skin pathologies such as atopic dermatitis (AD), psoriasis (PSO) and cancers, mainly via subcutaneous or intravenous routes. Finding new antibody delivery methods is a challenge and different technologies have emerged in recent years such as microneedle patches, nanoparticles, liposomes or gel formulations

\footnotetext{
*Correspondence: laurent.delpy@unilim.fr

${ }^{\dagger}$ Brigitte Closs-Gonthier and Laurent Delpy contributed equally to the work

${ }^{1}$ Unité Mixte de Recherche CNRS, 7276-INSERM U1262-Université de Limoges, CBRS, 2 rue du Dr Marcland, 87025 Limoges, France

Full list of author information is available at the end of the article
}

[1]. In addition, several modified antibodies are under development to treat cutaneous diseases, but at present, only certolizumab pegol, a PEGylated anti-tumor necrosis factor $\alpha$ antigen-binding fragment (Fab) has been approved (2013) for the treatment of PSO [1]. AD is an inflammatory skin disease with a high and constantly increasing prevalence worldwide $(1-3 \%$ of adults and $15-20 \%$ of children) [2]. This pathology is characterized by a skin barrier default and a Th2 phenotype with secretion of several proinflammatory cytokines such as interleukin-4 (IL-4), IL-5 and IL-13. Among them, IL-4 is particularly involved in immunoglobulin (Ig) class switching to IgE [3]. Different cell populations express the high affinity IgE receptor (FceRI) and immune complex original author(s) and the source, provide a link to the Creative Commons licence, and indicate if changes were made. The images or other third party material in this article are included in the article's Creative Commons licence, unless indicated otherwise in a credit line to the material. If material is not included in the article's Creative Commons licence and your intended use is not permitted by statutory regulation or exceeds the permitted use, you will need to obtain permission directly from the copyright holder. To view a copy of this licence, visit http://creativecommons.org/licenses/by/4.0/. The Creative Commons Public Domain Dedication waiver (http://creativeco mmons.org/publicdomain/zero/1.0/) applies to the data made available in this article, unless otherwise stated in a credit line to the data. 
phagocytosis by these cells leads to $\mathrm{T}$ lymphocytes activation [4]. Until now, only one immunotherapy treatment targeting the IL-4/IL-13 common receptor, IL-4 receptor alpha (IL-4R $\alpha$ ), has been approved for AD. Thus, developing a new topical immunotherapy treatment is a real challenge that would improve patients quality of life.

At present, there is no evidence in the literature proving that a reduced-size antibody could penetrate the skin more easily than a whole antibody. Thus, the first aim was to compare the passage of a single chain variable fragment $(\mathrm{scFv})(\sim 25 \mathrm{kDa})$ through a damaged skin, mimicking the poor barrier function of atopic skin, compared to a full-size monoclonal antibody (Ab) $(\sim 150 \mathrm{kDa})$. In addition, we addressed whether a scFv could neutralize the effects of human IL-4 (hIL-4) after stimulation of normal human keratinocytes (NHKs).

\section{Methods}

For the comparative study of the transcutaneous penetration of whole antibody and $\mathrm{scFv}$, ex vivo experiments were performed on pig ear skin. After shaving, ears were tape-stripped 25 times (Clinical\&Derm, USA) to obtain the altered skin condition. Then, $8 \mathrm{~mm}$ diameter punches were treated with $5 \mu \mathrm{l}$ phosphate buffered saline (PBS, Corning, USA), and $11 \mu \mathrm{M}$ anti-CD44 scFv (Creative Biolabs, USA) or anti-CD44 Ab (Thermofisher Scientific, USA). Skin samples were placed at $37{ }^{\circ} \mathrm{C}$ for $6 \mathrm{~h}$ or $24 \mathrm{~h}$ and cryopreserved until Raman microspectroscopy analysis.

Three $14 \mu \mathrm{m}$ thick sections were used per sample and three Raman acquisitions were read for each section totaling nine measures per sample. Briefly, Raman images were obtained using a confocal Raman microspectrometer (Horiba Jobin Yvon, France) operating with a $660 \mathrm{~nm}$ laser. Labspec 6 software (Horiba Jobin Yvon, France) was used for acquisition and data pre-processing. Raman maps were recorded in an area of $X: 10-\mu \mathrm{m} / \mathrm{Y}: 150-\mu \mathrm{m}$ with $5 \mu \mathrm{m}$ step size in the $\mathrm{XY}$ directions. Raman spectra were acquired in the $400-2300 \mathrm{~cm}^{-1}$ spectral range. To prevent background noise, Raman spectra were smoothed using a 2nd order Savitzky-Golay type filter, baseline corrected using a 7th order polynomial function, and spectra with an intensity under $400 \mathrm{cts}$ in the $1530-1730 \mathrm{~cm}^{-1}$ range were suppressed. Next, Raman spectra were cropped to keep only the $400-785 \mathrm{~cm}^{-1}$ range of interest, which was used for vector normalization. Finally, fitting (unmixing) by classical least squares with a non-negativity constraint (NCLS) was used to estimate the contribution of the various skin components leading to the images reflecting the distribution of the specific $\mathrm{scFv}$ or $\mathrm{Ab}$ through the skin cryo-sections.
To assess the neutralizing capacity of anti-hIL4 scFv in vitro, we used both a cell line model (HEK-Blue ${ }^{\mathrm{TM}}$ IL-4/IL-13 cells; InvivoGen, France) and NHKs as primary cells. HEK-Blue ${ }^{\mathrm{TM}}$ IL-4/IL-13 cells were cultured according to manufacturer's instructions. Briefly, 50,000 cells were seeded in 96-well plates. Then, cells were stimulated with $10 \mathrm{ng} / \mathrm{ml}$ hIL-4 (Miltenyi Biotec, Germany) and treated with anti-hIL4 scFv (Creative Biolabs, USA) or Ab (Biotechne, USA) at different concentrations. The variable domains of the anti-hIL4 $\mathrm{scFv}$ and monoclonal $\mathrm{Ab}$ are distincts and the latter was used as a positive control. After $24 \mathrm{~h}$, QUANTIBlue $^{\text {TM }}$ substrate was added to supernatants. After $2 \mathrm{~h} 30$ at $37^{\circ} \mathrm{C}$, SEAP levels were measured at $620 \mathrm{~nm}$ using a spectrophotometer.

NHKs were isolated from human skin samples from healthy donors $(n=4)$ undergoing medical surgery. The skin was collected after written informed consent from the donors and institutional approval. NHKs were stimulated with polyinosinic-polycytidylic acid (poly I:C) $(2 \mu \mathrm{g} / \mathrm{ml}$, Sigma, USA) $\pm \mathrm{hIL}-4(25 \mathrm{ng} / \mathrm{ml}$, Peprotech, USA) and treated with anti-hIL4 scFv at different concentrations. After $24 \mathrm{~h}$, supernatants were harvested to evaluate hIL-8 secretion by enzymelinked immunosorbent assay (ELISA) according to manufacturer's instructions (R\&D Systems, USA). Cell protein concentrations were determined using the BCA Protein Assay kit (Thermofisher Scientific, USA) according to manufacturer's instructions. hIL-8 secretion was normalized to total protein amounts.

Statistical analysis was performed using Prism GraphPad software (GraphPad Software, USA). Significant differences between samples and control were evaluated by Student's $t$-test. $P$ values $<0.05$ were considered significant.

Some detailed protocols are available in the Supporting Information.

\section{Results}

First, we used Raman microspectroscopy to assess the transcutaneous penetration of antibody formats using pig ear skin. Three distinct peaks from the skin signal, corresponding to the $\mathrm{scFv}$ and $\mathrm{Ab}$ specific Raman signatures, were identified in the spectral range between 400 and $785 \mathrm{~cm}^{-1}$ (Fig. 1a). This first analysis was necessary to visualize antibody penetration through the skin. At $6 \mathrm{~h}$, both $\mathrm{scFv}$ and $\mathrm{Ab}$ were only observed in the stratum corneum (depth: 10-20 $\mu \mathrm{m}$ ) (Fig. 1b). At $24 \mathrm{~h}$, scFv penetrated to a depth of $130 \mu \mathrm{m}$, corresponding to the upper papillary dermis while $\mathrm{Ab}$ remained on the surface (Fig. 1c). Results were obtained on altered skin samples. Hematoxylin and eosin staining (H\&E) of pig ear skin showed an altered skin barrier function 
(a)

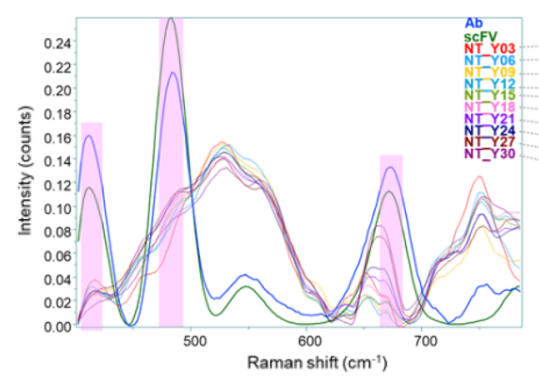

(b) T6h
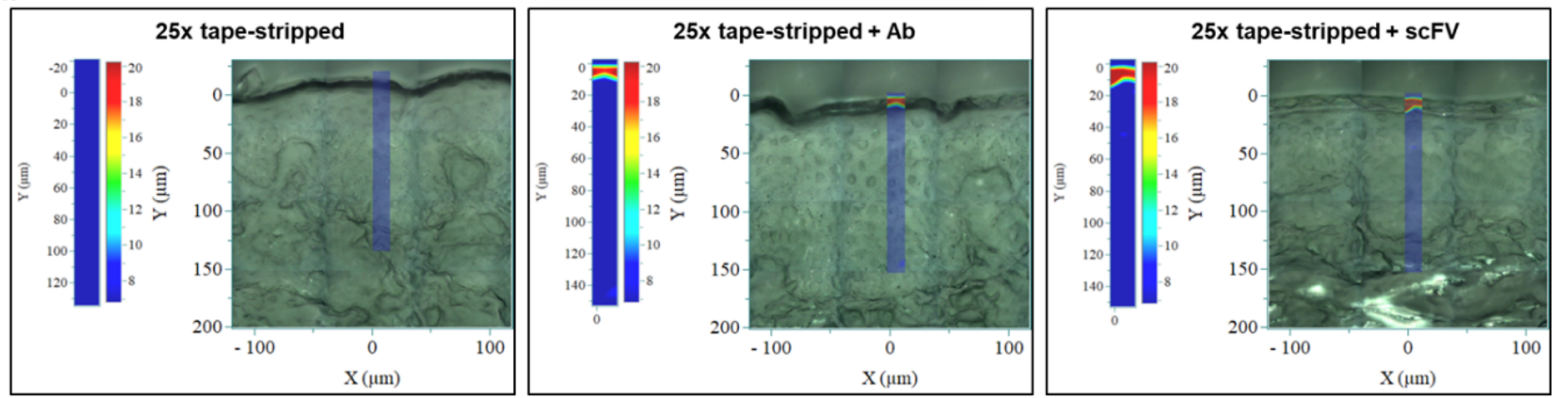

(c) T24h
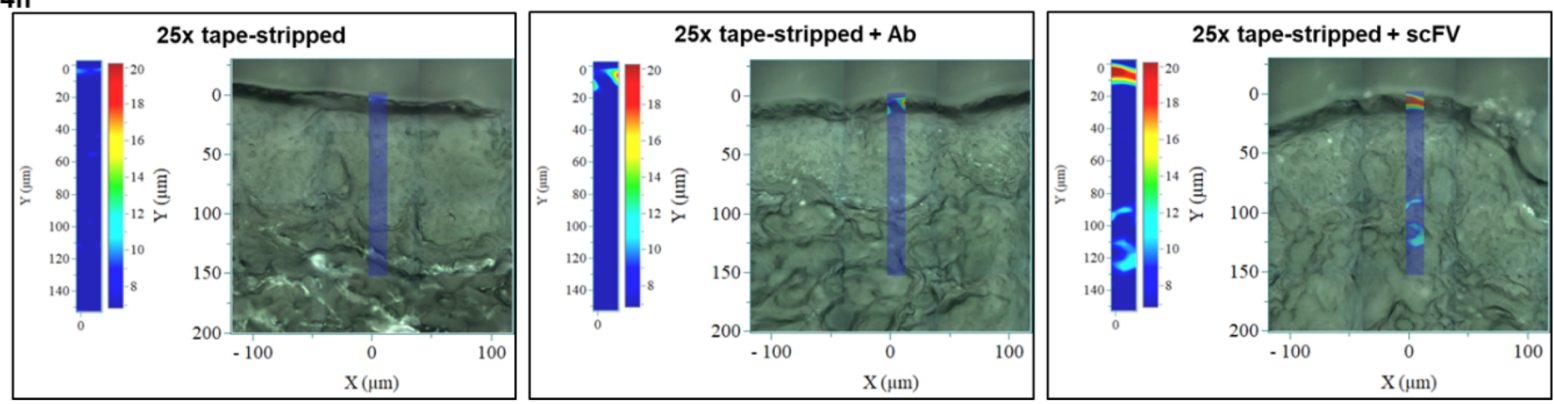

Fig. 1 Visualization of transcutaneous antibody penetration by Raman microspectroscopy. a Single-chain variable fragment (scFv) and antibody (Ab) Raman signals (highlighted in pink) and skin Raman signals at different depths between 400 and $785 \mathrm{~cm}^{-1}$. b Quantification of scFv and Ab in damaged skin after $6 \mathrm{~h}$ or (c) $24 \mathrm{~h}$ of treatment

on tape-stripped samples due to removal of part of the stratum corneum (Additional file 1: Figure S1).

Next, in vitro experiments were performed to assess the neutralizing capacity of anti-hIL4 scFv in HEK-Blue ${ }^{\mathrm{TM}}$ IL-4/IL-13 cells. Both the anti-hIL4 scFv and Ab showed significant dose-dependent neutralization of hIL-4 in the HEK Blue 2D model (Fig. 2a). In addition, at the maximal concentration of $200 \mathrm{nM}, \mathrm{scFv}$ neutralized an average of $68 \%$ of hIL-4 (Additional file 1: Table S1).

NHKs were then stimulated to evaluate hIL-4 neutralization by $\mathrm{scFv}$ on primary cells. hIL- 8 dosage of supernatants from NHKs stimulated with hIL- $4 \pm$ poly $\mathrm{I}: \mathrm{C}$ and treated with anti-hIL4 scFv, revealed a scFv dosedependent decrease in four different donors (Fig. 2b). At 100, 200, 400 and $600 \mathrm{nM}$ doses, a significant decrease in hIL-8 secretion was observed. ScFv neutralization ability against hIL-4 was calculated based on poly I:C induction of hIL-8. The hIL-4+ poly I:C was considered as the $0 \%$ of hIL-4 neutralization value, whereas poly I:C alone was considered as the $100 \%$ value (Table 1). At $600 \mathrm{nM} \mathrm{scFv}$, the average percentage of hIL-4 neutralization reached $80 \%$. Of note, the anti-hIL4 Ab used in this study showed low neutralization efficiency in this 2D model (data not shown).

\section{Discussion}

Until now, few studies assessing antibody penetration in the skin have been carried out. Among them, topical application of infliximab, an anti-TNF $\alpha \mathrm{Ab}$, has been described in patients with ulcers [5], and Flightless I (Flii) neutralizing antibodies (FnAb) have been applied in a murine model of epidermolysis bullosa acquisita 


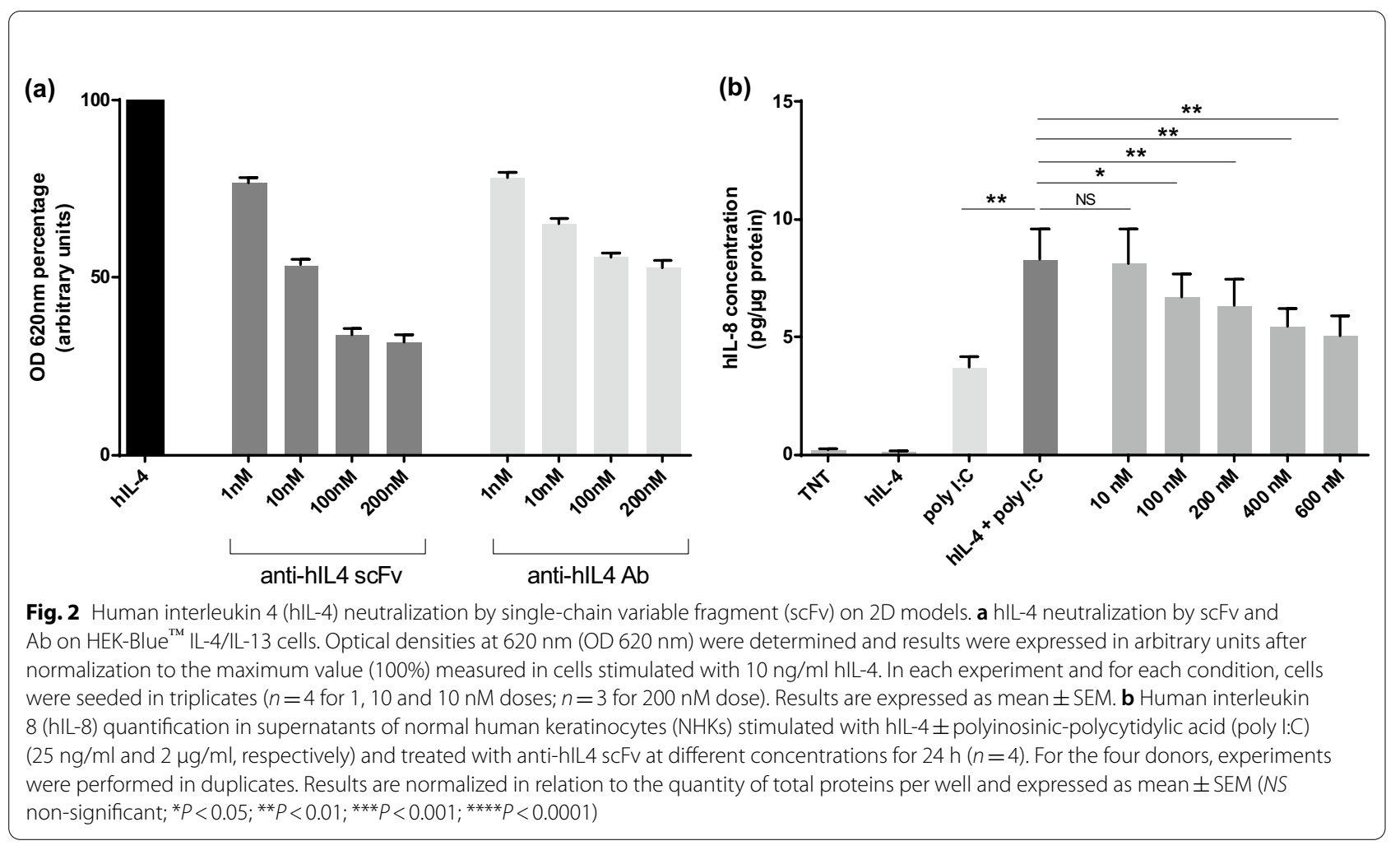

Table 1 hIL-4 neutralization by scFv in normal human keratinocytes (expressed as a relative percentage to poly I:C)

\begin{tabular}{|c|c|c|c|c|c|c|c|}
\hline Donors & poly I:C & hIL-4+ poly I:C & scFv $10 \mathrm{nM}$ & scFv $100 \mathrm{nM}$ & scFv $200 \mathrm{nM}$ & scFv $400 \mathrm{nM}$ & $\mathrm{scFv} 600 \mathrm{nM}$ \\
\hline D1 & 100 & 0 & -39 & 4 & 26 & 44 & 84 \\
\hline D2 & 100 & 0 & 69 & 84 & 118 & 113 & 127 \\
\hline D3 & 100 & 0 & 3 & 21 & 31 & 46 & 43 \\
\hline D4 & 100 & 0 & -7 & 33 & 28 & 58 & 64 \\
\hline Average (\%) & 100 & 0 & 7 & 36 & 51 & 65 & 80 \\
\hline Standard deviation (\%) & 0 & 0 & 45 & 35 & 45 & 32 & 36 \\
\hline
\end{tabular}

hIL-4 human interleukin 4, poly I:C polyinosinic-polycytidylic acid, scFv single chain variable fragment, $n M$ nanomolar

$[6,7]$. No comparative study examining the penetration of reduced-size versus whole antibodies has yet been performed, especially using Raman microspectroscopy, which is a relevant tool for antibody characterization. Indeed, this technique can be used to monitor posttranslational modifications, degradation or aggregation [8-10]. For several years, it has also been used to study the skin $[11,12]$. To our knowledge, we are the first to track antibody passage through the skin using Raman microspectroscopy. Here, we showed in an ex vivo model of damaged skin that reduced size facilitated antibody penetration into the upper papillary dermis.

Only one antibody fragment has been approved for the treatment of skin pathologies. Recently, M1095, an anti-IL17A/F nanobody completed a phase 1 clinical trial for the treatment of moderate to severe PSO [13]. Thus, antibody fragments could be potential tools for the development of new topical treatments for cutaneous diseases. Indeed, in recent years, innovative immunotherapy methods have emerged including microneedles, nanoparticles or liposomes [14-17]. To date, only one immunotherapy treatment has been approved for AD. Several treatments targeting proinflammatory molecules including cytokines and their receptors are under development for $\mathrm{AD}$ management [18]. First, we chose to target hIL-4, which is a key cytokine involved in $\mathrm{AD}$ physiopathology. In fact, it leads to B-lymphocytes class switching to IgE and naïve $T$ cells differentiation into Th2 [19]. Therefore, we decided to focus on the effect of hIL-4 
neutralization on inflammatory human keratinocytes. We found a scFv dose-dependent decrease in hIL-8 secretion suggesting a key role for hIL-4 in inflammation. In addition, our results showed a strong neutralization efficiency of anti-hIL4 scFv on HEKBlue ${ }^{\mathrm{TM}}$ IL-4/IL-13 cells.

A limitation of our ex vivo model could be the lack of lesional AD human skin biopsies. Tape strips represent a simple and easy way to mimic barrier disruption, feature observed in the pathology. Nevertheless, this alteration does not reflect all structural changes of atopic skin, suggesting a different behavior of scFv penetration on patient's skin that would need to be assessed. In the future, it would be interesting to evaluate the benefits of a topical anti-mouse IL-4 treatment on an in vivo AD model such as NC/Nga mice [20].

To sum up, we showed that reduced-size antibodies depict better penetration abilities than full-size antibodies and retain high capacity to neutralize a cytokine target. Reduced-size antibodies could be therefore potential relevant topical treatments for inflammatory skin diseases as AD.

\section{Supplementary Information}

The online version contains supplementary material available at https://doi. org/10.1186/s13223-021-00574-x.

Additional file 1: Fig. S1. Representative images for hematoxylin and eosin staining ( $H \& E)$ of pig ear skin samples (a) with no treatment or (b) times tape-stripped to mimic damaged skin. Table S1: hIL-4 neutralization by scFv in HEK-Blue ${ }^{\mathrm{TM}} \mathrm{IL}-4 / \mathrm{IL}-13$ cells (expressed as a relative percentage to OD620 nm).

\section{Acknowledgements}

We would like to thank all the members of the UMR CNRS 7276-INSERM U 1262 research unit for helpful discussions and comments and Jeanne CookMoreau for proofreading of the manuscript. We would also like to thank all the members of Silab R\&D and more specifically Nathalie Solingeas and Elodie Brugère for their technical expertise.

\section{Authors' contributions}

$A B$ performed experiments and was a major contributor in writing the manuscript. RV analyzed and interpreted Raman spectroscopy. ML, LM, CM, SB, BCG and LD supervised the study and and reviewed the manuscript. All authors read and approved the final manuscript.

\section{Funding}

This work was supported by grants from Silab R\&D. A.B. was a recipient of a Ph.D. CIFRE-ANRT fellowship from the French government.

\section{Availability of data and materials}

The datasets used and/or analysed during the current study are available from the corresponding author on reasonable request.

\section{Declarations}

Ethics approval and consent to participate

Normal human keratinocytes (NHKs) were isolated from human skin samples from healthy donors undergoing medical surgery. The skin was collected after written informed consent from the donors and institutional approval.
Consent for publication

Not applicable.

\section{Competing interests}

The authors declare that they have no competing interests.

\section{Author details}

${ }^{1}$ Unité Mixte de Recherche CNRS, 7276-INSERM U1262-Université de Limoges, CBRS, 2 rue du Dr Marcland, 87025 Limoges, France. ${ }^{2}$ Silab R\&D Department, Brive, France.

Received: 3 May 2021 Accepted: 28 June 2021

Published online: 19 July 2021

\section{References}

1 Baylet A, Laclaverie M, Marchand L, Bordes S, Closs-Gonthier B, Delpy L. Immunotherapies in cutaneous pathologies: an overview. Drug Discov Today. 2021;26(1):248-55.

2. Nutten S. Atopic dermatitis: global epidemiology and risk factors. Ann Nutr Metab. 2015;66(1):8-16.

3. Mu Z, Zhao Y, Liu X, Chang C, Zhang J. Molecular biology of atopic dermatitis. Clin Rev Allergy Immunol. 2014;47(2):193-218.

4 Liu F-T, Goodarzi H, Chen H-Y. IgE, mast cells, and eosinophils in atopic dermatitis. Clin Rev Allergy Immunol. 2011;41(3):298-310.

5. Streit M, Beleznay Z, Braathen LR. Topical application of the tumour necrosis factor-a antibody infliximab improves healing of chronic wounds. Int Wound J. 2006:3(3):171-9.

6 Kopecki Z, Ruzehaji N, Turner C, Iwata H, Ludwig RJ, Zillikens D, et al. Topically applied flightless I neutralizing antibodies improve healing of blistered skin in a murine model of epidermolysis bullosa acquisita. J Invest Dermatol. 2013;133(4):1008-16.

7. Haidari H, Zhang Q, Melville E, Kopecki Z, Song Y, Cowin AJ, et al. Development of topical delivery systems for flightless neutralizing antibody. J Pharm Sci. 2017;106(7):1795-804

8. McAvan BS, Bowsher LA, Powell T, O'Hara JF, Spitali M, Goodacre R, et al. Raman spectroscopy to monitor post-translational modifications and degradation in monoclonal antibody therapeutics. Anal Chem. 2020;92(15):10381-9.

9. Sane SU, Wong R, Hsu CC. Raman spectroscopic characterization of drying-induced structural changes in a therapeutic antibody: correlating structural changes with long-term stability. J Pharm Sci. 2004;93(4):1005-18.

10 Ettah I, Ashton L. Engaging with Raman spectroscopy to investigate antibody aggregation. Antibodies. 2018:7(3):24.

11 Gniadecka M, Nielsen OF, Christensen DH, Wulf HC. Structure of water, proteins, and lipids in intact human skin, hair, and nail. J Invest Dermatol. 1998; 110(4):393-8.

12. Barry BW, Edwards HGM, Williams AC. Fourier transform Raman and infrared vibrational study of human skin: assignment of spectral bands. J Raman Spectrosc. 1992;23(11):641-5.

13. Svecova D. A randomized, double-blind, placebo-controlled phase 1 study of multiple ascending doses of subcutaneous M1095, an antiinterleukin 17A/F nanobody, in moderate-to-severe psoriasis. J Am Acad Dermatol. 2019;81(1):8.

14. Wang C, Ye Y, Hochu GM, Sadeghifar H, Gu Z. Enhanced cancer immunotherapy by microneedle patch-assisted delivery of anti-PD1 antibody. Nano Lett. 2016;16(4):2334-40.

15. Ferreira M, Barreiros L, Segundo MA, Torres T, Selores M, Costa Lima SA, et al. Topical co-delivery of methotrexate and etanercept using lipid nanoparticles: a targeted approach for psoriasis management. Colloids Surf B Biointerfaces. 2017;159:23-9.

16. Petrilli R, Eloy J, Lopez R, Lee R. Cetuximab immunoliposomes enhance delivery of 5-FU to skin squamous carcinoma cells. Anticancer Agents Med Chem. 2017;17(2):301-8.

17 Chen X, Zhang Z, Yang S, Chen H, Wang D, Li J. All-trans retinoic acidencapsulated, CD20 antibody-conjugated poly(lactic-co-glycolic acid) nanoparticles effectively target and eliminate melanoma-initiating cells in vitro. OncoTargets Ther. 2018;11:6177-87. 
18. Luger T, Dirschka T, Eyerich K, Gollnick H, Gupta G, Lambert J, et al. Developments and challenges in dermatology: an update from the Interactive Derma Academy (IDeA) 2019. J Eur Acad Dermatol Venereol. 2020;34(S7):3-18.

19. Guttman-Yassky E, Bissonnette R, Ungar B, Suárez-Fariñas M, Ardeleanu M Esaki $\mathrm{H}$, et al. Dupilumab progressively improves systemic and cutaneous abnormalities in patients with atopic dermatitis. J Allergy Clin Immunol. 2019;143(1):155-72.

20. Kim Y-J, Choi MJ, Bak D-H, Lee BC, Ko EJ, Ahn GR, et al. Topical administration of EGF suppresses immune response and protects skin barrier in DNCB-induced atopic dermatitis in NC/Nga mice. Sci Rep. 2018;8(1):11895.

\section{Publisher's Note}

Springer Nature remains neutral with regard to jurisdictional claims in published maps and institutional affiliations.
Ready to submit your research? Choose BMC and benefit from:

- fast, convenient online submission

- thorough peer review by experienced researchers in your field

- rapid publication on acceptance

- support for research data, including large and complex data types

- gold Open Access which fosters wider collaboration and increased citations

- maximum visibility for your research: over $100 \mathrm{M}$ website views per year

At BMC, research is always in progress.

Learn more biomedcentral.com/submissions 